\title{
COMPRESSIONAL PROPERTIES OF PARACETAMOL TABLET FORMULATIONS CONTAINING MODIFIED STARCH, POLYVINYLPYRROLIDONE AND MAIZE STARCH BP AS BINDERS.
}

\author{
Mohammed BB \\ Department of Pharmaceutics and Pharmaceutical Microbiology, Ahmadu Bello University, Zaria, Nigeria \\ Presenting Author's Email: disciplebbm@gmail.com, Telephone: +2348067728578
}

Received 27 Nov 2012; Review Completed 15 Dec 2012; Accepted 08 Jan 2013, Available online 15 Jan 2013

\begin{abstract}
The compressional properties of paracetamol tablet formulations containing modified starch (acid hydrolysed), Polyvinylpyrrolidone and maize starch as binders have been investigated. Paracetamol granules obtained by wet massing at varying binder concentrations were compacted using a hydraulic press at different tabletting pressures $\left(28.31-141.56 \mathrm{MNm}^{-2}\right)$. Density measurements and the compression equations of Heckel and Kawakita were used as assessment parameters where the following variables $\mathbf{P}_{\mathbf{Y}}, \mathbf{D}_{\mathbf{A}}, \mathbf{D}_{\mathbf{B}}, \mathbf{D o}, \mathbf{P}_{\mathbf{k}}$, and $\mathbf{D}_{\mathbf{I}}$ were investigated. Formulations containing modified starch showed a slower onset of plastic deformation due to a high mean yield pressure while that of PVP showed the highest onset of plastic deformation. Maize starch BP had the lowest $\mathrm{P}_{\mathrm{K}}$ value indicating the highest total plastic deformation occurring during compression while modified starch had the highest $\mathrm{P}_{\mathrm{K}}$ value owing to a lesser total plastic deformation showing that there is a correlation between the compression equations of Heckel and Kawakita as assessment parameters and that modified cassava starch could be useful as a binder in paracetamol tablet formulations to produce tablets with desired compressional properties for particular purposes.

Keywords: Modified starch, Polyvinylpyrrolidone (PVP), Heckel equation, Kawakita equation, plastic deformation.
\end{abstract}

\section{INTRODUCTION}

Starch is one of the traditional excipients used in the manufacture of tablets. Depending on the application, specific starches are available for use as binders, diluents, and/or disintegrants. The use of this natural polymeric material is based on its adhesive, thickening, gelling, swelling and film forming properties, as well as its availability. Starch continues to be attractive as a binding material because of its abundant supply, low cost, biodegradability, and ease of chemical modification ${ }^{3}$.

Cassava starch has been found to be useful in the role of a binder in particular tablet formulations. It is however important to characterize the compaction properties of these binders in order to determine the optimum conditions to which they should be subjected during tableting process. The compression properties of pharmaceutical powders have been characterized using density measurements and the Heckel and Kawakita equations.

The Heckel equation ${ }^{4}$ is widely used for relating the relative density, $\mathrm{D}$, of a powder bed during compression to the applied pressure, $\mathrm{P}$. It is written as:

$$
\operatorname{In}[1 /(1-\mathrm{D}]=\mathrm{KP}+\mathrm{A} \text {. }
$$

The slope of the straight line portion, $\mathrm{K}$, is the reciprocal of the mean yield pressure, Py, of the material. From the value of $\mathrm{A}$, the intercept, the relative density $\mathrm{D}_{\mathrm{A}}$, can be calculated using the following equation;

$$
\mathrm{D}_{\mathrm{A}}=1-\mathrm{e}^{-\mathrm{A}}
$$

The relative density of the powder at the point when the applied pressure equals zero, $D_{0}$, is used to describe the initial rearrangement phase of densification as a result of die filling. The relative density $D_{B}$, describes the phase of rearrangement at low pressures and is the difference between $D_{A}$ and $D_{O}$

$$
\mathrm{D}_{\mathrm{B}}=\mathrm{D}_{\mathrm{A}}-\mathrm{D}_{\mathrm{O}}
$$

The Kawakita equation ${ }^{5}$ is used to study powder compression using the degree of volume reduction (C) and is written as:

$$
\mathrm{C}=\left(\mathrm{V}_{\mathrm{O}}-\mathrm{V}_{\mathrm{P}}\right) / \mathrm{V}_{\mathrm{O}}=\mathrm{abP} /(1+\mathrm{bP})
$$

The equation, in practice can be rearranged to give:

$$
\mathrm{P} / \mathrm{C}=\mathrm{p} / \mathrm{a}+1 / \mathrm{ab}
$$

Where $V_{O}$ is the initial bulk volume of powder and $V_{P}$ is the bulk volume after compression. The constant $\mathbf{a}$ is equal to the minimum porosity of the material before compression while the constant $\mathbf{b}$ is related to the plasticity of the material. The reciprocal of $\mathbf{b}$ given a pressure term $\mathrm{P}_{\mathrm{K}}$ which is the pressure required to reduce the powder bed by $50 \%$.

In the present work, a study has been made of the compaction properties of modified cassava starch, used as binder in comparison with those of polyvinylpyrrolidone and maize starch BP in paracetamol tablet formulations.

Paracetamol was chosen because it possesses poor compression properties and therefore requires a binder to form good quality tablets.

\section{EXPERIMENTAL}

\section{Material}

The materials used were paracetamol powder, maize starch BP, polyvinylpyrrolidone (PVP), hydrochloric acid 


\section{Mohammed et al}

Journal of Drug Deliver

and Talc powder (May and Baker Ltd, England), magnesium stearate (Merck, Germany), cassava starch obtained from the tubers of Manihot esculenta, family: Euphorbiaceae, (prepared in other laboratory). The extraction of the cassava starch was carried out as described by Linus ${ }^{7}$. The method used for the modification was the same as that reported by WIPO ${ }^{14}$.

\section{Methods}

\section{Bulk and tapped densities}

A $50 \mathrm{~g}$ quantity was weighed and transferred into a $100 \mathrm{ml}$ measuring cylinder. The cylinder was allowed to fall on a wooden platform from a height of $2.5 \mathrm{~cm}$ there times at 2 seconds intervals. The volume occupied by the starch was recorded as the bulk volume. The cylinder was then tapped on the wooden platform until the volume occupied by the starch remained constant. This was repeated three times and average bulk and tapped volumes recorded. The data generated were used in computing the Bulk and Tapped densities as well as $\mathrm{D}_{\mathrm{O}}$.

\section{Formulation of paracetamol tablets}

\section{Table 1: Tablet Formula}

\begin{tabular}{|ll|}
\hline $\begin{array}{c}\text { Material } \\
(\mathrm{mg})\end{array}$ & Weight per tablet \\
\hline Paracetamol powder & 500 \\
Maize starch (Endo-disintegrant) & 50 \\
Binder* & $\mathrm{qs}$ \\
Talc & $2 \% \mathrm{w} / \mathrm{w}$ \\
Magnesium stearate & $0.2 \% \mathrm{w} / \mathrm{w}$ \\
Maize starch (Exo-disintegrant) & $7.8 \% \mathrm{w} / \mathrm{w}$ \\
\hline
\end{tabular}

Key: -

*MCS--- Microcrystalline starch $(2.5,5.0,7.5,10) \%$ w/v

*PVP--- Polyvinylpyrrolidone $(2.5,5.0,7.5,10) \%$ w/v

*MS---- Maize starch mucilage $(2.5,5.0,7.5,10) \%$ w $/ \mathrm{v}$

\section{Compression of Tablets}

Compacts equivalent to $500 \mathrm{mg}$ paracetamol were produced by compressing the granules for 30s with predetermined loads (at various compression pressures) using a hydraulic carver press (model, C, serial no 34000 - y \& Therapeutics; 2013, 3(1), 11-14

289, China). 10 tablets were compacted at each pressure. All read readings are average of 3 measurements. Before each compression, the die $(10.5 \mathrm{~mm}$ in diameter) and flat faced punches were lubricated with a $1 \% \mathrm{w} / \mathrm{v}$ dispersion of magnesium stearate in ethanol. After ejection, the tablets were stored over silica gel in a dessicator for $24 \mathrm{~h}$ to allow for elastic recovery and hardening to prevent false low yield values ${ }^{6}$ and the dimensions of the compact were determined using the digital caliper (Z540 - 1, USA) to the nearest $0.01 \mathrm{~mm}$. Their relative densities (D) were calculated using the equation:

$\mathrm{D}={ }^{\mathrm{w}} /{ }_{\mathrm{vps}}$ where $\mathrm{V}_{\mathrm{t}}$ is the volume $\left(\mathrm{cm}^{3}\right)$ of the tablet, and $\rho \mathrm{s}$ is the particle density $\left(\mathrm{gcm}^{-3}\right)$ of the solid material.

Heckel plots of $\operatorname{In}(1 / 1-\mathrm{D})$ versus applied pressure $(\mathrm{P})$ and Kawakita plots of $\mathrm{P} / \mathrm{C}$ versus $\mathrm{P}$, were constructed for all binders.

\section{RESULTS AND DISCUSSION}

The Heckel plots for paracetamol tablets containing $10 \%(\mathrm{w} / \mathrm{v})$ binder concentration for hydrolysed starch, polyvinylpyrrolidone (PVP) and maize starch BP (MS) gave a linear relationship was obtained with the correlation coefficient of $\geq 0.990$ indicating deformation mainly by plastic flow ${ }^{8}$.

The values of the mean yield pressure, $\mathrm{Py}, \mathrm{D}_{\mathrm{O}}, \mathrm{D}_{\mathrm{A}}$ and $\mathrm{D}_{\mathrm{B}}$ for the various binders are presented in Table 2. The ranking for Py was HS > MS > PVP; for $\mathrm{D}_{\mathrm{O}}$ and $\mathrm{D}_{\mathrm{A}}$, MS > PVP > HS and for $\mathrm{D}_{\mathrm{B}}$, PVP > MS > HS. The value of $\mathrm{D}_{\mathrm{O}}$ represents the degree of initial packing in the die as a result of die filling for the binders. Hydrolysed starch exhibited the lowest value, this could be attributed to the particle sizes (5-12) $\mu \mathrm{m}$ which are small leading to more mechanical and electrostatic forces to prevent packing ${ }^{\mathbf{1 2}}$. But for maize starch binder which had the highest value of $\mathrm{D}_{\mathrm{O}}$, could be due to the decrease in the electrostatic forces responsible for preventing closer packing of particles ${ }^{\mathbf{1 0}}$. The value of $\mathrm{D}_{\mathrm{A}}$, which represents the total degree of packing at zero and low pressures, showed that maize starch had the highest value and HS the lowest. This could still be related to the size and shapes of the particles ${ }^{\mathbf{1 2}}$.

Table 2: Parameters derived from density measurements and Heckel and Kawakita plots

\begin{tabular}{|l|c|c|c|c|c|c|}
\hline \multicolumn{1}{|c|}{ Binder Type } & $\mathbf{D}_{\mathbf{O}}$ & $\begin{array}{c}\mathbf{P y} \\
\left(\mathbf{M N m}^{-2}\right)\end{array}$ & $\mathbf{D}_{\mathbf{A}}$ & $\mathbf{D}_{\mathbf{B}}$ & $\begin{array}{c}\mathbf{P}_{\mathbf{K}} \\
\left(\mathbf{M N m}^{-\mathbf{2}}\right)\end{array}$ & $\begin{array}{c}\mathbf{D}_{\mathbf{I}} \\
(\mathbf{1}-\mathbf{a})\end{array}$ \\
\hline Hydrolysed starch & 0.32 & 226.5 & 0.791 & 0.471 & 3.33 & 0.35 \\
\hline Polyvinylpyrrolidone & 0.35 & 149.8 & 0.873 & 0.523 & 2.17 & 0.36 \\
\hline Maize starch BP & 0.37 & 192.6 & 0.891 & 0.521 & 1.54 & 0.38 \\
\hline
\end{tabular}

$D_{B}$ represents the phase of rearrangement of the particles in the early stages of compression. The rearrangement of particles occurs more with smaller particle size (PVP) and less with larger and irregular particle sizes (MS and HS $)^{\mathbf{1 3}}$. The mean yield pressure Py is inversely related to the ability of the binders to deform plastically under pressure. The results indicate that PVP exhibits the fastest onset of plastic deformation during compression while HS exhibits the slowest rate. This indicates that PVP is soft and ductile and readily deforms plastically during compression ${ }^{10}$.
The Kawakita plots for paracetamol tablet formulations containing $10 \% \mathrm{w} / \mathrm{v}$ binder concentration for hydrolysed starch, polyvinylpyrrolidone and maize starch BP are presented in Figure 2. A linear relationship was also obtained at all compression pressures employed with correlation coefficient of 0.999 for all binders. Values of a and $\mathbf{a b}$ were obtained from the slope and intercept of the plots respectively. Values of -a gives initial relative density of the formulations $\mathbf{D}_{\mathbf{I}}$ while $\mathbf{P}_{\mathbf{K}}$ values of $\mathbf{D}_{\mathbf{I}}$ and $\mathbf{P}_{\mathbf{K}}$ are included in Table 2. 
The values of $D_{\text {I }}$ which is a measure of the packed initial relative density of the formulations with the application of small pressures or tapping ${ }^{11}$ was in the rank order $\mathbf{M S}>$
PVP > HS. These values were also seen to be slightly higher than the values of loose initial relative density $\mathrm{D}_{\mathrm{O}}$.

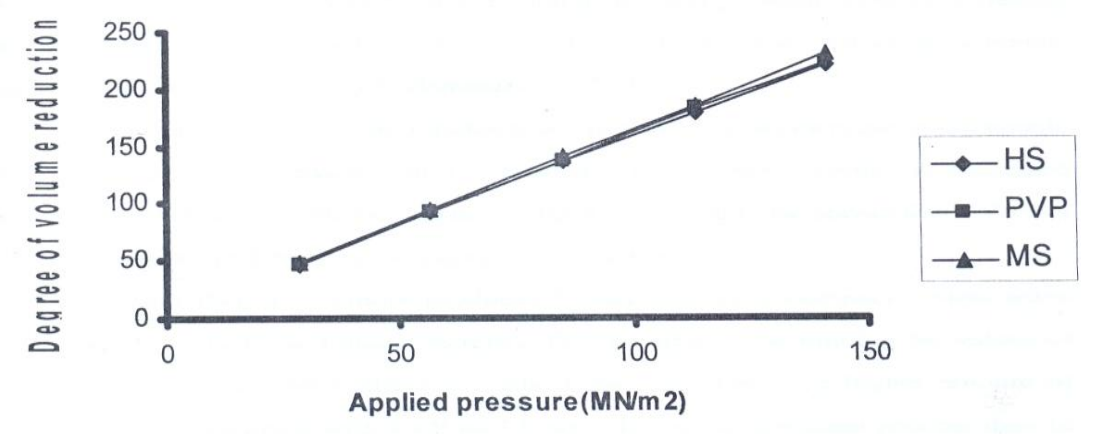

Figure 1: Kawakita plots for paracetamol tablets containing $10 \%(\mathrm{w} / \mathrm{v})$ binder
concentrations. HS, PVP, MS

This is in agreement with previous work ${ }^{\mathbf{1 1}}$. The values of $\mathrm{P}_{\mathrm{K}}$, which is an inverse measure of the amount of plastic deformation occurring during the compression process were in the rank order HS > PVP > MS. The low value of $P_{K}$ is indicative of the reduction in cohesion due to the presence of a binder. Binders are generally expected to reduce the cohesiveness and increase flow of granulations ${ }^{1}$. A low value of $P_{K}$ is also indicative of materials that are soft and that readily deform plastically under pressure ${ }^{2}$. It has also been established that the lower the $\mathrm{P}_{\mathrm{K}}$ value, the more the total plastic deformation $\left(\mathrm{D}_{\mathrm{A}}\right)$ occuring during compression ${ }^{\mathbf{1 1}}$. This is the basis of correlation between the Heckel and Kawakita plots. This indicates that HS exhibited the lowest amounts of plastic deformation while MS showed the highest amount of plastic deformation during the compression process.

Comparing the results on compressional characteristics i.e. between $\mathrm{Py}$ and $\mathrm{P}_{\mathrm{K}}$, Odeku and Itiola ${ }^{11}$ have shown that Py relates essentially to the onset of plastic deformation during compression, while $\mathrm{P}_{\mathrm{K}}$, relates to the amount of plastic deformation occurring during compression process.

\section{REFERENCES}

1. Alebiowu, G and Itiola OA. Effect of natural and pregelatinized sorghum, plantain and corn starch Binders on the compressional characteristics of a paracetamol formulation in Drug Delivery (Supplement to Pharmaceutical Technology (Ed.S. Schuber) Advantsar Publishing Corporation, Oregon, 2001, pp. 26-30.

2. Emeje, M, Isimi, C, and Kunle O. Effect of Grewia gum on the mechanical properties of paracetamol tablet formulations. African Journal of Pharmacy and Pharmacology,,2008 Vol. (2). Pp.001-006.

3. Geber-Mariam T, Schimidt PC. Characterization of enset starch and its use as a binder and disintegrant for tablets. Pharmazie, 1996, 51: 303-311

4. Heckel RW. Density-pressure relationships in powder compaction. Trans. Metal. Soc. AIME.1961, 221: 671-675

5. Kawakita $\mathrm{K}$ and Ludde KH. Some considerations on powder compression equations. Powder Technol.1970-71, 4:61-68

6. Krycer I, Pope DG, Hersey JA. An evaluation of the Technique employed to investigate powder compaction behavior. Int. J. Pharm. 1982 , 12:113-134.

7. Linus A.J, Tabletting behaviour of some depolymerized local starches M.Sc (Pharmaceutics) thesis work. Ahmadu Bello University Zaria, Nigeria.1995, P.42-45

\section{CONCLUSION}

The results of this present work showed that all the formulations containing the different binders deformed by plastic flow ${ }^{8}$. It also showed that in tablet formulations, those containing PVP would be more useful in minimizing the problems of lamination and capping especially on high speed tabletting machine with short dwell time for plastic deformation of materials while formulations containing hydrolysed starch as binder would be more useful when high bond strength of the tablet is desired. Thus, hydrolyzed cassava starch could be useful as a binder in paracetamol tablet formulations to produce tablets with desired compressional properties.

\section{ACKNOWLEDGEMENT}

The author is grateful to the technical staff of the Department of Pharmaceutics \& Pharm. Microbiology, Ahmadu Bello University, Zaria.

8. Mohammed, B.B, Isah, A.B and Ibrahim, M.A. Influence of Compaction Pressures on Modified Cassava Starch as a binder in Paracetamol tablet formulations. Nig. Journ. Pharm. Sci, 2009, Vol.8 No.1, p.80- 88

9. Odeku OA, Awe OO, Popoola B, Itiola OA. "Compression and mechanical properties of tablet formulations, containing corn, sweet potato, and cocoyam starch as binders" $w w w$. Pharmtech.com, pp 2005, 82-90.

10. Odeku OA, Picker-fryer, KM. Analysis of the material properties, tableting and tablet formation properties of four dioscore starches, starch/strake 2007, 59430-444

11. Odeku, OA and Itiola, OA. Evaluation of Khaya gum as a binder in Paracetamol Tablet Formulation. Pharm. Pharmcol. Commun. 1998, 4:183 - 188 .

12. Paronen $P$ and Juslin M. Compressional characteristics of four starch. J. Pharm. Pharmacol. 1983, 35:637-635

13. Rippie EG. Mixing. In: Lieberman, H.A and Kanin, J .L. (Eds), Theory and practice of Industral Phamacy, $3^{\text {rd }}$ Edition Lea and febiger, Philadelpling, 1986, 13-20

14. W.I.P.O., World Intellectual Property Organization. Use of microcrystalline starch as tabletting excipient. 1997, PCT/NL97/00097 